Article

\title{
Simplified Neutrosophic Exponential Similarity Measures for Evaluation of Smart Port Development
}

\author{
Jihong Chen ${ }^{1,2} \oplus$, Kai Xue ${ }^{1}$, Jun Ye ${ }^{3, *} \mathbb{0}$, Tiancun Huang ${ }^{1, *}$, Yan Tian ${ }^{2}$, Chengying Hua ${ }^{1}$ and \\ Yuhua Zhu ${ }^{4}$ \\ 1 College of Transport and Communications, Shanghai Maritime University, Shanghai 201306, China; \\ cxjh2004@163.com (J.C.); rookiex23@163.com (K.X.); 201830610136@stu.shmtu.edu.cn (C.H.) \\ 2 School of Business, Beijing Institute of Technology, Zhuhai, Zhuhai 519088, China; Tandty@163.com \\ 3 Department of Electrical and Information Engineering, Shaoxing University, Shaoxing 312000, China \\ 4 School of Management, Fudan University, Shanghai 200433, China; yhzhu@shmtu.edu.cn \\ * Correspondence: yehjun@aliyun.com (J.Y.); huangtiancun1563@163.com (T.H.); \\ Tel.: +86-575-8832-7323 (J.Y.); +86-21-3828-2334 (T.H.)
}

Received: 30 January 2019; Accepted: 29 March 2019; Published: 3 April 2019

\begin{abstract}
Smart ports represent the current trend of port development. Intelligent operations reduce the daily production cost of ports, facilitate efficient production, strengthen the risk mitigation ability and comply with the requirements for long-term development. However, a systematic and scientific smart port evaluation method is missing to nail down the evaluation indicators of a smart port and enable accurate evaluation of a port's degree of intelligence. This paper analyzes the concept of the smart port, establishes a set of smart port evaluation indicator systems, and applies a single-valued neutrosophic exponential similarity measure to port evaluation to enable quantitative evaluation of port integrity. This evaluation method is capable of decision-making in the event of incomplete, uncertain, and inconsistent information during general evaluation, opening up a new method for smart port evaluation, and acting as a helpful tool for ports to carry out improvements during actual application.
\end{abstract}

Keywords: smart port; simplified neutrosophic set; single-valued neutrosophic set; exponential similarity measure; port evaluation

\section{Introduction}

More and more opportunities for international trade cooperation are emerging as the world economy integrates. Ports, as a key link in global transportation, play an important role in world economic and trade development. However, currently port enterprises are battling sluggish growth of revenue and cutthroat competition due to homogenization. The international community is paying increasing attention to environmental protection issues, demonstrating higher sensitivity to climate change issues. All these problems have been pushing ports toward upgrading and transformation. In recent years, smart ports have become a dominant mode for port development, representing the highest level of modern port development. Smart port is based on systematic, strategic and social thinking, featuring integrated application of cloud computing, big data, Internet of Things, mobile internet, intelligent sensing and other next-generation information technologies to achieve all-round perception, ubiquitous interconnection, intelligent integration, deep computing, and coordinated operation and promoting organic connection and sharing of various resource elements and related parties in the port organization ecosystem, so as to eventually form a modern port that is smarter, safer, more efficient, more flexible, greener, and with strong cultural presence. 
To materialize an operation mode for the smart port, scholars have conducted a ton of research on port optimization, including improving logistics supply efficiency, enhancing port service functions, reducing environmental pollution at ports, and cutting energy consumption of equipment. These studies have provided practical and effective steps to port organizations and improved their shortcomings. However, the current evaluation of smart port performance remains imperfect, lacking an objective and scientific evaluation method, and clear indicators for the evaluation, which is not conducive to discovering problems in ports. For the purpose of establishing a systematic and scientific smart port evaluation approach, this paper builds up a system of indicators for smart port evaluation, namely by using single-valued neutrosophic exponential similarity measure to quantify the degree of port intelligence. The research results can offer a theoretical basis for the port industry and stakeholders to launch smart port construction.

The rest of the paper is organized as follows. The literature review in Section 2 summarizes the current research programs on port efficiency evaluation with the aim to draw lessons from them. Section 3 determines the smart port evaluation indicators. Section 4 proposes the research approach in this paper, and introduces the neutrosophic exponential similarity measure. Section 5 conducts an empirical study to evaluate smart port based on the indicators in a simplified neutrosophic environment. Section 6 presents the conclusion of this paper.

\section{Literature Review}

Development efficiency evaluation helps ports to identify their own shortcomings, and facilitates better designing of plans and policies tailored to distinct situations of different ports, which is of constructive significance for port development. At present, parametric analysis and nonparametric analysis are two dominant approaches for port efficiency evaluation both domestically and internationally. Specifically, data envelopment analysis (DEA) is often used in the nonparametric analysis. Scholars select different input and output indicators from different angles according to their own research needs, and construct corresponding port operation efficiency evaluation models. Wu et al. used the DEA model to test the sensitivity of individual input and output decision-making units, finding that berth count and capital investment are the most sensitive factors affecting the throughput of a container port [1]. Tongzon studied the operational efficiency of international ports with the DEA model, and compared the operational advantages of several international ports, discovering that the relationship between the efficiency of an international port and its size is not clear [2,3]. Cullinane et al. took into account time-varying factors in port efficiency evaluation modeling, and established the DEA time window analysis model to study the relative efficiencies of world's major container ports, finding that the evaluated efficiency of a container port fluctuates over time [4]. Cullinane et al. studied the advantages and disadvantages of port privatization, and used the DEA model to conduct an empirical study on the relationship between privatization and container port efficiency [5]. Rajasekar and Deo studied the size effect and its efficiency of Indian Major Ports using DEA-Additive models, discovering that there is no significant difference between size and its efficiency of the port [6]. Wang and Han used the traditional DEA, into fuzzy DEA using fuzzy number characteristics in order to measure the efficiency of twelve international container ports in Taiwan and surrounding areas without having to consider weighting values of inputs and outputs. This approach allows objective and easy measurement of international container port efficiency. By the fuzzy DEA computation, it was found that the results of judging under input orientation and output orientation were consistent [7]. Cullinane and Wang studied the fundamentals of DEA and demonstrated how DEA can be applied to measure the efficiency of container ports. As a benchmarking approach to study efficiency, DEA enables a port to evaluate its performance vis-a-vis its peers. In so doing, the possible waste of resources and the industry best practice can be identified [8]. Gamassa and Chen used the DEA model to measured and analyzed the East and West African major ports efficiency over time, and the findings demonstrate that though West African ports have bigger ports size and have a higher Container throughput TEUs compared to East African ports [9]. In addition, Chin et al. used the DEA model to study the 
efficiencies of ports in Singapore, Greece, ASEAN, etc., and proposed enhanced measures targeting their shortcomings [10-12].

The parametric approach for port efficiency evaluation primarily uses the so-called stochastic frontier analysis. The stochastic frontier analysis refers to calculating the deviation degree between the sample port and frontier ports in terms of efficiency to evaluate the efficiency of the sample port. There are no definite frontier ports in terms of efficiency, they are just the most efficient ports relative to other ports, and vary with different port sample sets [13]. Coto-Millan et al. used a stochastic frontier cost function to evaluate the economic efficiency of Spanish ports using panel data, and found that the port operation model has a significant impact on economic efficiency, but the port size has no relationship with port economic efficiency [14]. Cullinane et al. used the cross-section and panel data versions of the "stochastic frontier model" to evaluate the relative efficiency of major container ports in Asia, and found that port size is closely related to port efficiency [15]. Notteboom and Winkelmans used the Bayesian stochastic frontier model to evaluate the port efficiency in Asia and Europe, and found that port efficiency has nothing to do with privatization but is positively related to port size [16]. In addition, many scholars used the analytical hierarchy process to evaluate port performance [17-19], the fuzzy analytical network process (FANP), and other multiple attribute decision-making methods were also chosen to evaluate port efficiency [20,21]. Such evaluation methods are easier for practical application, but feature international indicators of the evaluation system and hence a high degree of interference.

Founded by Smarandache in 1980, neutrosophy studies the neutrosophic origin, nature and scope, as well as the roles of different ideologies [22]. In recent years, neutrosophic set theory has been widely used in decision-making and evaluation research in many industries. Neutrosophy boasts wide application, such as in the fields of engineering, medicine, military science, cybernetics and physics, for logical deduction, aggregation, and probability statistics. Fu and Ye proposed new exponential similarity measures (ESMs) between simplified neutrosophic sets (SNSs), including single-valued neutrosophic ESMs and interval neutrosophic ESMs, and their initial evaluation/diagnosis method of the BPH symptoms with simplified neutrosophic information [23]. Peng et al. proposed simplified neutrosophic sets for multi-criteria decision-making problems [24]. Sahin and Liu used two new operational laws in which the bases are positive real numbers and interval numbers, respectively and the exponents are SNNs, and discussed some of their desired properties [25]. Şahin and Küçük established a useful method dealing with subsethood similarity measure between two SVNSs [26]. Biswas et al. applied the TOPSIS method in single-valued neutrosophic information [27]. Şahin and Liu introduced a maximizing deviation method under neutrosophic environment and utilized it for solving a numerical example with incomplete weight information [28]. Akram and Shahzadi defined the notion of the interval valued neutrosophic soft set (ivn-soft sets), which is a combination of an interval valued neutrosophic set and a soft set to investigate the decision making based on ivn-soft sets by level soft sets [29]. Smarandache and Ali introduced the notion of neutrosophic triplet, which is a group of three elements that satisfy certain properties with some binary operation [30]. Rizk-Allah et al. developed a new compromise algorithm for multi-objective transportation problem (MO-TP), which is inspired by Zimmermann's fuzzy programming and the neutrosophic set terminology [31]. Liu and Teng introduced the definition, the properties, the score function, the accuracy function, and the operational laws of the normal neutrosophic numbers (NNNs), and used an illustrative example to demonstrate the practicality and effectiveness of the proposed method [32]. Abdel-Basset and Mohamed proposed a general framework for smart city evaluation with imperfect and incomplete information through using single valued neutrosophic and rough set theories [33]. Thong et al. developed a new Technique for Order of Preference by Similarity to Ideal Solution (TOPSIS) method based on the proposed Dynamic Interval-valued Neutrosophic Set(DIVNS) theory [34]. However, neutrosophy in the field of transportation application is rarely mentioned, so this paper proposes to apply a single-valued neutrosophic exponential similarity measure to evaluate smart port in a simplified neutral environment. 
Most of the current research on port efficiency evaluation adopts the aforementioned methods, or makes further improvements based on the aforesaid studies. In recent years, some new non-classical nature-inspired evaluation and optimization methods have also been developed and applied [35-37]. However, port evaluation indicators are uncertain in practical application, no matter whether the parametric analysis or the nonparametric analysis approach is used for port performance evaluation. Besides, the evaluation indicators for different ports are not consistent and applying different evaluation methods for the same port will also produce different results. To avoid this, we should nail down the indicators related to smart port evaluation and then use the single-valued neutrosophic exponential similarity measure to evaluate smart port on that basis.

\section{Evaluating Indicators}

Port is the junction of water and land transport, an important base for industrial activities, a comprehensive logistics center and a new growth point for urban economic development. To facilitate more efficient, safer and greener port operation, experts never ceased the search of new information technologies, and the concept of the smart port came into being.

Currently, the smart port in the broad sense is a result of digital technologies, business model innovation and resource value innovation. The smart port features excellent port operation, an open ecosystem, and active expansion in sustainable innovative businesses.

Smart ports attempt to apply advanced information technology as well as automated and intelligent mechanical equipment to the daily production and operation management of ports, realizing the automation of port production and operation, the whole process of port logistics supply chain services, the facilitation of port financial trade and the rationalization of port energy saving and emission reduction. Smart ports enable seamless connection and synergy between vehicles, ships, people, cargoes and various systems of the port, improving its daily operational efficiency and amplifying its advantages. By referring to literature in port and related fields, this paper singles out specific evaluation indicators for the smart port, as shown in Table 1. The smart port mentioned in this paper refers to a comprehensive conceptual port, which renders intelligence and advancedness to the port in terms of production and operation systems, logistics supply chain systems, financial and trade service technologies, and energy conservation and emission reduction capacities. This enables a safe, efficient, convenient, green and sustainable development form of the port to improve the comprehensive competitiveness of ports.

Specifically, the evaluation indicators of the port production and operation systems include the application of emerging information technologies, such as port production dispatching automation, Internet of Things and cloud computing, and emergency response capabilities. These indicators emphasize the application of intelligent technology in port operation, which is the breakthrough sign of the development of information and intelligence in many ports in the world. Smart Ports use intelligent technology to automate production scheduling, reduce manual work, and enhance the handling capacity of port emergency events.

The evaluation indicators of the port logistics supply chain systems include the intelligent level of door-to-door full-course services of port logistics, the electronic processing of logistics documents, the standardization level of operations and the "Internet + " logistics supply chain services of the port. These indicators mainly consider the ability of ports to develop door-to-door supply chain services, especially require ports to realize the intellectualization, standardization, and convenience of logistics services through intelligent technology. Ports can provide efficient, fast, and convenient integrated logistics services.

The evaluation indicators of the port financial and trade service technologies include port integration and facilitation as well as customs clearance efficiency, and sharing of financial service resources in the port supply chain. These indicators consider the service expansion capability of ports in the context of intellectualization, and require ports to use intelligent technology to achieve convenient customs clearance environment, goods trade, and supply chain financial service extension. 
The evaluation indicators of the port energy conservation and emission reduction capacities include the application status of green energy sources at the port and the emission control and governance capacities over port pollutants. These indicators mainly consider how to use intelligent technology to achieve energy reduction and emission reduction, and how to build and develop green ports. Green port is also a new concept of port development in the world. It is a sustainable port with a good balance between environmental protection and economic interests. Guided by the concept of green development, green ports achieve environmental health, energy consumption reduction, and pollution reduction through intelligent technologies and emission reduction measures.

Table 1. Classification of Smart Port Evaluation Indicators.

\begin{tabular}{|c|c|c|}
\hline Area & Evaluation Indicator & Reference \\
\hline \multirow{3}{*}{$\begin{array}{l}\text { Port Production and } \\
\text { Operation Systems }\end{array}$} & Production dispatching automation & [38-40] \\
\hline & $\begin{array}{l}\text { Application of emerging information technologies at ports } \\
\text { such as the Internet of Things and cloud computing }\end{array}$ & {$[39,41,42]$} \\
\hline & Emergency response capabilities & {$[38,41]$} \\
\hline \multirow{3}{*}{$\begin{array}{l}\text { Port Logistics Supply } \\
\text { Chain System }\end{array}$} & $\begin{array}{l}\text { Intelligent level of door-to-door full-course services of } \\
\text { port logistics }\end{array}$ & [40-43] \\
\hline & $\begin{array}{l}\text { Electronic processing of logistics documents, the } \\
\text { standardization level of operations }\end{array}$ & [40-43] \\
\hline & "Internet + " logistics supply chain services & [40-43] \\
\hline \multirow{2}{*}{$\begin{array}{l}\text { Port Financial and Trade } \\
\text { Service Technologies }\end{array}$} & $\begin{array}{l}\text { Port integration and facilitation as well as customs } \\
\text { clearance efficiency }\end{array}$ & {$[38,44,45]$} \\
\hline & Sharing of financial service resources in the port supply chain & {$[44,45]$} \\
\hline \multirow{2}{*}{$\begin{array}{l}\text { Port Energy Conservation and } \\
\text { Emission Reduction Capacities }\end{array}$} & Application status of green energy sources at the port & {$[38,46,47]$} \\
\hline & $\begin{array}{l}\text { Emission control and governance capacities over } \\
\text { port pollutants }\end{array}$ & [46-49] \\
\hline
\end{tabular}

\section{Research Methodology}

\subsection{Basic Concepts of SNSs}

Simplified neutrosophic set (SNS) is a powerful tool that attracts the attention of many scholars in dealing with uncertainty and vagueness [24]. Ye proposed the Simplified Neutrosophic Set (SNS), a subset of the neutrosophic set which is more suitable for processing issues that contain many incomplete, uncertain, and inconsistent information to apply neutrosophy to science and engineering better $[23,26]$. SNS can be defined as follows.

Let $X$ be a space of points (objects), with a generic element in $X$ denoted by $x$. An SNS $N$ in $X$ is characterized by a truth-membership function $T_{N}(x)$, an indeterminacy-membership function $I_{N}(x)$ and a falsity-membership function $F_{N}(x)$. Then, an SNS $N$ can be expressed as $N=\left\{<x, T_{N}(x), I_{N}(x)\right.$, $\left.F_{N}(x)>\mid x \in X\right\}$, where the sum of $T_{N}(x), I_{N}(x), F_{N}(x) \subseteq[0,1]$ satisfies the condition $0 \leq \sup T_{N}(x)+\sup$ $I_{N}(x)+\sup F_{N}(x) \leq 3$ for each point $x$ in $X$. Then, SNS is a subclass of the neutrosophic set and includes the concepts of single valued neutrosophic set (SVNS).

Assume that $A=\left\{<x, T_{A}(x), I_{A}(x), F_{A}(x)>\mid x \in X\right\}$ and $B=\left\{<x, T_{B}(x), I_{B}(x), F_{B}(x)>\mid x \in X\right\}$ are two SNSs, where $T_{A}(x), I_{A}(x), F_{A}(x) \in[0,1], 0 \leq T_{A}(x)+I_{A}(x)+F_{A}(x) \leq 3$ for each point $x$ in $X$, i.e., $A$ and $B$ are two Simplified Neutrosophic Sets (SNSs). The SNS is a effective generalization of the fuzzy set that is designed for some situations in which each element has different truth membership function, indeterminacy membership function and falsity membership function. Then, the inclusion, equation, and complement for SNSs $A$ and $B$ are defined, respectively, as follows:

(1) $B \subseteq A$ if and only if $T_{A}(x) \leq T_{B}(x), I_{A}(x) \geq I_{B}(x), F_{A}(x) \geq F_{B}(x)$ for any $x$ in $X$, 
(2) $A=B$ if and only if $A \subseteq B$ and $B \subseteq A$,

(3) $A^{c}=\left\{<x, F_{A}(x), 1-I_{A}(x), T_{A}(x)>\mid x \in X\right\}$ and $B^{c}=\left\{<x, F_{B}(x), 1-I_{B}(x), T_{B}(x)>\mid x \in X\right\}$.

Assume that $A=\left\{\left\langle x, T_{A}(x), I_{A}(x), F_{A}(x)\right\rangle \mid x \in X\right\}$ and $B=\left\{\left\langle x, T_{B}(x), I_{B}(x), F_{B}(x)\right\rangle \mid x \in X\right\}$ are two SNSs in $X$. If $T_{A}(x), I_{A}(x), F_{A}(x) \subseteq[0,1], 0 \leq \sup T_{A}(x)+\sup I_{A}(x)+\sup F_{A}(x) \leq 3, T_{B}(x), I_{B}(x), F_{B}(x)$ $\subseteq[0,1]$, and $0 \leq \sup T_{B}(x)+\sup I_{B}(x)+\sup F_{B}(x) \leq 3$ for each point $x$ in $X$, then $A$ and $B$ are reduced to two interval neutrosophic sets (INSs) [50]. Thus, the inclusion, equation, and complement for SNSs $\mathrm{B}$ and $\mathrm{A}$ are defined, respectively, as follows:

(4) $B \subseteq A$ if and only if inf $T_{B}(x) \leq \inf T_{A}(x), \inf I_{B}(x) \geq \inf I_{A}(x), \inf F_{B}(x) \geq \inf F_{A}(x), \sup T_{B}(x) \leq$ $\sup T_{A}(x), \sup I_{B}(x) \geq \sup I_{A}(x), \sup F_{B}(x) \geq \sup F_{A}(x)$ for any $x$ in $X$;

(5) $B=A$ if and only if $B \subseteq A$ and $A \subseteq B$;

(6) $A^{c}=\left\{\left\langle x,\left[\inf F_{A}(x), \sup F_{A}(x)\right],\left[1-\sup I_{A}(x), 1-\inf I_{A}(x)\right],\left[\inf T_{A}(x), \sup T_{A}(x)\right]\right\rangle \mid x \in X\right\}$ and $B^{c}$ $=\left\{\left\langle x,\left[\inf F_{B}(x), \sup F_{B}(x)\right],\left[1-\sup I_{B}(x), 1-\inf I_{B}(x)\right],\left[\inf T_{B}(x), \sup T_{B}(x)\right]\right\rangle \mid x \in X\right\}$

Especially when the upper and lower ends of the interval numbers $T_{A}(x), I_{A}(x), F_{A}(x)$ in $\mathrm{A}$ and $T_{B}(x), I_{B}(x), F_{B}(x)$ in $B$ are equal, the INSs $A$ and $B$ are reduced to the single valued neutrosophic sets (SVNSs) A and B. Therefore, SVNSs are the special cases of INSs, and also SVNSs and INSs are also the special cases of SNSs.

\subsection{Exponential Similarity Measures of SVNS}

The single valued neutrosophic set (SVNS) is a generalization of classic set, fuzzy set, interval valued fuzzy set, intuitionistic fuzzy set, and para-consistent set $[23,26]$. This section describes the steps of applying the exponential similarity measuring method, as detailed below.

Step 1. Determine the decision goal. This paper aims to obtain the evaluation approach of smart port, consulting relevant literature to determine the specific indicators of the evaluation system. $I_{m}$ represents the $m$-th indicator.

Step 2. Develop criteria for indicators. According to different evaluation environments, different degrees of decision-making statuses are selected, and $D_{n}$ is used to denote the $n$-th degree. Second, these degrees are represented by their respective SVNS information.

Step 3. Conduct a preliminary evaluation. $t$ industry experts are invited to evaluate the indicators. Truth, Indeterminacy, and Falsity represent the degree of recognition, from high to low, of the indicator performance. Specific SVNS value calculation is as follows:

Assume $a$ experts select Truth, $b$ experts choose Indeterminacy, and $c$ experts choose Falsity. Then the SNS value of this indicator is $\langle a / t, b / t, c / t\rangle$.

Step 4. Exponential similarity measure. Set the standard to be $A=\left\{<x_{j}, T_{A}\left(x_{j}\right), I_{A}\left(x_{j}\right), F_{A}\left(x_{j}\right)>\mid x_{j} \in\right.$ $X\}$, and the preliminary evaluation is $B=\left\{<x_{j}, T_{B}\left(x_{j},\right), I_{B}\left(x_{j}\right), F_{B}\left(x_{j}\right)>\mid x \in X\right\}$, which is any two SVNSs in the range of $X=\left\{x_{1}, x_{2}, \ldots, x_{m}\right\}$. Based on the exponential function, the exponential similarity measure of the standard and the preliminary evaluation is defined as follows:

$$
E_{i}(A, B)=\frac{1}{m} \sum_{j=1}^{m} \frac{\exp \left\{-\frac{1}{3}\left[\left|T_{A}\left(x_{j}\right)-T_{B}\left(x_{j}\right)\right|+\left|I_{A}\left(x_{j}\right)-I_{B}\left(x_{j}\right)\right|+\left|F_{A}\left(x_{j}\right)-F_{B}\left(x_{j}\right)\right|\right]\right\}-\exp (-1)}{1-\exp (-1)}
$$

When the weights of the indicators are different, a weight coefficient $w_{j}$ can be added. $w_{j} \in[0,1]$ and the sum of them is 1 . The specific expression is as follows:

$$
W_{i}(A, B)=\sum_{j=1}^{m} w_{j} \frac{\exp \left\{-\frac{1}{3}\left[\left|T_{A}\left(x_{j}\right)-T_{B}\left(x_{j}\right)\right|+\left|I_{A}\left(x_{j}\right)-I_{B}\left(x_{j}\right)\right|+\left|F_{A}\left(x_{j}\right)-F_{B}\left(x_{j}\right)\right|\right]\right\}-\exp (-1)}{1-\exp (-1)}
$$

Step 5. Make the calculation using MATLAB. The above content is coded and calculated in MATLAB to obtain the maximum similarity measure to indicate the most appropriate evaluation. 


\section{Application Method and Results}

In this section, the aforementioned methods will apply. First, follow Step 1 to organize the smart port evaluation indicators listed above into the Table 2.

Table 2. Evaluation by 5 experts for a port $P_{k}$.

\begin{tabular}{|c|c|c|c|}
\hline \multirow{2}{*}{ Indicators } & Truth & Indeterminacy & Falsity \\
\hline & $(\mathrm{T})$ & (I) & (F) \\
\hline \\
\hline \multirow{2}{*}{\multicolumn{4}{|c|}{$\begin{array}{l}I_{2} \text { The application of the Internet of things, cloud computing and } \\
\text { other emerging information technologies in ports }\end{array}$}} \\
\hline & & & \\
\hline \multicolumn{4}{|l|}{$I_{3}$ The ability of the port to deal with emergencies } \\
\hline \multicolumn{4}{|l|}{$I_{4}$ Intelligent level of port logistics door-to-door service } \\
\hline \multicolumn{4}{|l|}{$\begin{array}{c}I_{5} \text { Port logistics documents, data processing and other links electronic, } \\
\text { standardized operation level }\end{array}$} \\
\hline \multicolumn{4}{|l|}{$I_{6}$ Port “Internet +" logistics supply chain service } \\
\hline \multicolumn{4}{|l|}{$I_{7}$ Integration and facilitation of ports and customs } \\
\hline \multicolumn{4}{|l|}{ clearance efficiency } \\
\hline \multicolumn{4}{|l|}{$I_{8}$ Port supply chain financial service resource sharing } \\
\hline \multicolumn{4}{|l|}{$I_{9}$ Application of green energy in ports } \\
\hline \multicolumn{4}{|l|}{$I_{10}$ The ability to control and control the discharge of pollutants } \\
\hline from ports & & & \\
\hline
\end{tabular}

Follow Step 2 to preliminarily classify smart port into five degrees: strong, relatively strong, average, relatively weak, and weak, to quantify the initially evaluated degrees of the smart port. See Table 3 for details.

Table 3. Five types of smart port degree with simplified neutrosophic information.

\begin{tabular}{cccccc}
\hline \multirow{2}{*}{ Indicators } & $\boldsymbol{D}_{\mathbf{1}}$ & $\boldsymbol{D}_{\mathbf{2}}$ & $\boldsymbol{D}_{\mathbf{3}}$ & $\boldsymbol{D}_{\mathbf{4}}$ & $\boldsymbol{D}_{\mathbf{5}}$ \\
\cline { 2 - 6 } & $\mathbf{( S t r o n g )}$ & (Relatively Strong) & (Average) & (Relatively Weak) & (Weak) \\
\hline$I_{1}$ & $<1.0,0.0,0.0>$ & $<0.8,0.2,0.0>$ & $<0.6,0.4,0.0>$ & $<0.4,0.4,0.2>$ & $<0.2,0.4,0.4>$ \\
$I_{2}$ & $<1.0,0.0,0.0>$ & $<0.8,0.2,0.0>$ & $<0.6,0.4,0.0>$ & $<0.4,0.4,0.2>$ & $<0.2,0.4,0.4>$ \\
$I_{3}$ & $<1.0,0.0,0.0>$ & $<0.8,0.2,0.0>$ & $<0.6,0.4,0.0>$ & $<0.4,0.4,0.2>$ & $<0.2,0.4,0.4>$ \\
$I_{4}$ & $<1.0,0.0,0.0>$ & $<0.8,0.2,0.0>$ & $<0.6,0.4,0.0>$ & $<0.4,0.4,0.2>$ & $<0.2,0.4,0.4>$ \\
$I_{5}$ & $<1.0,0.0,0.0>$ & $<0.8,0.2,0.0>$ & $<0.6,0.4,0.0>$ & $<0.4,0.4,0.2>$ & $<0.2,0.4,0.4>$ \\
$I_{6}$ & $<1.0,0.0,0.0>$ & $<0.8,0.2,0.0>$ & $<0.6,0.4,0.0>$ & $<0.4,0.4,0.2>$ & $<0.2,0.4,0.4>$ \\
$I_{7}$ & $<1.0,0.0,0.0>$ & $<0.8,0.2,0.0>$ & $<0.6,0.4,0.0>$ & $<0.4,0.4,0.2>$ & $<0.2,0.4,0.4>$ \\
$I_{8}$ & $<1.0,0.0,0.0>$ & $<0.8,0.2,0.0>$ & $<0.6,0.4,0.0>$ & $<0.4,0.4,0.2>$ & $<0.2,0.4,0.4>$ \\
$I_{9}$ & $<1.0,0.0,0.0>$ & $<0.8,0.2,0.0>$ & $<0.6,0.4,0.0>$ & $<0.4,0.4,0.2>$ & $<0.2,0.4,0.4>$ \\
$I_{10}$ & $<1.0,0.0,0.0>$ & $<0.8,0.2,0.0>$ & $<0.6,0.4,0.0>$ & $<0.4,0.4,0.2>$ & $<0.2,0.4,0.4>$ \\
\hline
\end{tabular}

From Table 3 we can see that the evaluated degrees of smart port indicators correspond to the following SVNS information.

$S_{1}=\left\{\left\langle I_{1}, 1.0,0.0,0.0\right\rangle,\left\langle I_{2}, 1.0,0.0,0.0\right\rangle,\left\langle I_{3}, 1.0,0.0,0.0\right\rangle,\left\langle I_{4}, 1.0,0.0,0.0\right\rangle,\left\langle I_{5}, 1.0,0.0,0.0\right\rangle,\left\langle I_{6}, 1.0,0.0,0.0\right\rangle\right.$, $\left.<I_{7}, 1.0,0.0,0.0>,<I_{8}, 1.0,0.0,0.0>,<I_{9}, 1.0,0.0,0.0>,<I_{10}, 1.0,0.0,0.0>\right\}$,

$S_{2}=\left\{\left\langle I_{1}, 0.8,0.2,0.0\right\rangle,\left\langle I_{2}, 0.8,0.2,0.0\right\rangle,\left\langle I_{3}, 0.8,0.2,0.0\right\rangle,\left\langle I_{4}, 0.8,0.2,0.0\right\rangle,\left\langle I_{5}, 0.8,0.2,0.0\right\rangle,\left\langle I_{6}, 0.8,0.2,0.0\right\rangle\right.$, $\left.<I_{7}, 0.8,0.2,0.0>,<I_{8}, 0.8,0.2,0.0>,<I_{9}, 0.8,0.2,0.0>,<I_{10}, 0.8,0.2,0.0>\right\}$,

$S_{3}=\left\{\left\langle I_{1}, 0.6,0.4,0.0\right\rangle,\left\langle I_{2}, 0.6,0.4,0.0\right\rangle,\left\langle I_{3}, 0.6,0.4,0.0\right\rangle,\left\langle I_{4}, 0.6,0.4,0.0\right\rangle,\left\langle I_{5}, 0.6,0.4,0.0\right\rangle,\left\langle I_{6}, 0.6,0.4,0.0\right\rangle\right.$, $\left.<I_{7}, 0.6,0.4,0.0>,<I_{8}, 0.6,0.4,0.0>,<I_{9}, 0.6,0.4,0.0>,<I_{10}, 0.6,0.4,0.0>\right\}$,

$S_{4}=\left\{\left\langle I_{1}, 0.4,0.4,0.2\right\rangle,\left\langle I_{2}, 0.4,0.4,0.2\right\rangle,\left\langle I_{3}, 0.4,0.4,0.2\right\rangle,\left\langle I_{4}, 0.4,0.4,0.2\right\rangle,\left\langle I_{5}, 0.4,0.4,0.2\right\rangle,\left\langle I_{6}, 0.4,0.4,0.2\right\rangle\right.$, $\left.<I_{7}, 0.4,0.4,0.2>,<I_{8}, 0.4,0.4,0.2>,<I_{9}, 0.4,0.4,0.2>,<I_{10}, 0.4,0.4,0.2>\right\}$,

$S_{5}=\left\{\left\langle I_{1}, 0.2,0.4,0.4>,\left\langle I_{2}, 0.2,0.4,0.4\right\rangle,\left\langle I_{3}, 0.2,0.4,0.4>,\left\langle I_{4}, 0.2,0.4,0.4\right\rangle,\left\langle I_{5}, 0.2,0.4,0.4\right\rangle,\left\langle I_{6}, 0.2,0.4,0.4\right\rangle\right.\right.\right.$, $\left.<I_{7}, 0.2,0.4,0.4>,<I_{8}, 0.2,0.4,0.4>,<I_{9}, 0.2,0.4,0.4>,<I_{10}, 0.2,0.4,0.4>\right\}$. 
Follow Step 3 to provide Table 2 to five experts for parallel preliminary evaluation of the three ports. The evaluation results are shown in Table 4.

Table 4. Five experts' evaluation of three smart ports.

\begin{tabular}{cccccccccc}
\hline \multirow{2}{*}{ Indicators } & \multicolumn{3}{c}{ Port A } & \multicolumn{3}{c}{ Port B } & \multicolumn{3}{c}{ Port C } \\
\cline { 2 - 9 } & $\mathbf{T}$ & $\mathbf{I}$ & $\mathbf{F}$ & $\mathbf{T}$ & $\mathbf{I}$ & $\mathbf{F}$ & $\mathbf{T}$ & $\mathbf{I}$ & $\mathbf{F}$ \\
\hline$I_{1}$ & $5 / 5$ & $0 / 5$ & $0 / 5$ & $4 / 5$ & $0 / 5$ & $1 / 5$ & $3 / 5$ & $1 / 5$ & $1 / 5$ \\
$I_{2}$ & $4 / 5$ & $1 / 5$ & $0 / 5$ & $3 / 5$ & $2 / 5$ & $0 / 5$ & $3 / 5$ & $0 / 5$ & $2 / 5$ \\
$I_{3}$ & $4 / 5$ & $0 / 5$ & $1 / 5$ & $2 / 5$ & $0 / 5$ & $3 / 5$ & $1 / 5$ & $1 / 5$ & $3 / 5$ \\
$I_{4}$ & $3 / 5$ & $2 / 5$ & $0 / 5$ & $4 / 5$ & $1 / 5$ & $0 / 5$ & $4 / 5$ & $0 / 5$ & $1 / 5$ \\
$I_{5}$ & $4 / 5$ & $1 / 5$ & $0 / 5$ & $3 / 5$ & $1 / 5$ & $1 / 5$ & $2 / 5$ & $1 / 5$ & $2 / 5$ \\
$I_{6}$ & $5 / 5$ & $0 / 5$ & $0 / 5$ & $3 / 5$ & $1 / 5$ & $1 / 5$ & $3 / 5$ & $1 / 5$ & $1 / 5$ \\
$I_{7}$ & $3 / 5$ & $0 / 5$ & $2 / 5$ & $4 / 5$ & $0 / 5$ & $1 / 5$ & $2 / 5$ & $2 / 5$ & $1 / 5$ \\
$I_{8}$ & $4 / 5$ & $1 / 5$ & $0 / 5$ & $3 / 5$ & $1 / 5$ & $1 / 5$ & $4 / 5$ & $1 / 5$ & $0 / 5$ \\
$I_{9}$ & $5 / 5$ & $0 / 5$ & $0 / 5$ & $3 / 5$ & $0 / 5$ & $2 / 5$ & $2 / 5$ & $3 / 5$ & $0 / 5$ \\
$I_{10}$ & $3 / 5$ & $2 / 5$ & $0 / 5$ & $2 / 5$ & $2 / 5$ & $1 / 5$ & $3 / 5$ & $2 / 5$ & $0 / 5$ \\
\hline
\end{tabular}

From Table 4, the indicator degrees of Port $P_{k}(k=1,2,3)$ can be expressed with the following SVNS information:

$P_{1}=\left\{\left\langle I_{1}, 1.0,0.0,0.0\right\rangle,\left\langle I_{2}, 0.8,0.2,0.0\right\rangle,\left\langle I_{3}, 0.8,0.0,0.2\right\rangle,\left\langle I_{4}, 0.6,0.4,0.0\right\rangle,\left\langle I_{5}, 0.8,0.2,0.0\right\rangle,\left\langle I_{6}, 1.0,0.0,0.0\right\rangle\right.$, $\left.<I_{7}, 0.6,0.0,0.4>,<I_{8}, 0.8,0.2,0.0>,<I_{9}, 1.0,0.0,0.0>,<I_{10}, 0.6,0.0,4.0>\right\}$,

$P_{2}=\left\{\left\langle I_{1}, 0.8,0.0,0.2\right\rangle,\left\langle I_{2}, 0.6,0.4,0.0\right\rangle,\left\langle I_{3}, 0.4,0.0,0.6\right\rangle,\left\langle I_{4}, 0.8,0.2,0.0\right\rangle,\left\langle I_{5}, 0.6,0.2,0.2\right\rangle,\left\langle I_{6}, 0.6,0.2,0.2\right\rangle\right.$, $\left.<I_{7}, 0.8,0.0,0.2>,<I_{8}, 0.6,0.2,0.2>,<I_{9}, 0.6,0.0,0.4>,<I_{10}, 0.4,0.4,0.2>\right\}$,

$P_{3}=\left\{\left\langle I_{1}, 0.6,0.2,0.2\right\rangle,\left\langle I_{2}, 0.6,0.0,0.4\right\rangle,\left\langle I_{3}, 0.2,0.2,0.6\right\rangle,\left\langle I_{4}, 0.8,0.0,0.2\right\rangle,\left\langle I_{5}, 0.4,0.2,0.4\right\rangle,\left\langle I_{6}, 0.6,0.2,0.2\right\rangle\right.$, $\left.<I_{7}, 0.4,0.4,0.2>,<I_{8}, 0.8,0.2,0.0>,<I_{9}, 0.4,0.6,0.0>,<I_{10}, 0.6,0.4,0.0>\right\}$.

According to Step 4, assume that the weight of each element $I_{j}$ is $w_{j}=1 / 10$ for $j=1,2, \ldots, 10$. Then, by using MTALAB, we can get the results of the similarity measure between the port $P_{k}(k=1,2,3)$ and the indicator degree $D_{i}(i=1,2,3,4,5)$, as shown in Table 5 .

Table 5. Similarity measure values of between $P_{k}$ and $D_{i}$ with SVNSs.

\begin{tabular}{cccccc}
\hline & $S_{1}$ & $S_{2}$ & $S_{3}$ & $S_{4}$ & $S_{5}$ \\
\hline$W_{1}\left(P_{1}, D_{i}\right)$ & 0.8099 & 0.8445 & 0.7556 & 0.6189 & 0.4841 \\
$W_{1}\left(P_{2}, D_{i}\right)$ & 0.6340 & 0.7356 & 0.7380 & 0.7531 & 0.6167 \\
$W_{1}\left(P_{3}, D_{i}\right)$ & 0.5905 & 0.7207 & 0.7380 & 0.7531 & 0.6513 \\
\hline
\end{tabular}

In Table 5, the maximum similarity measure indicates the most proper evaluation. In the three smart ports, the result of port $P_{1}$ is "Relative Strong", that of port $P_{2}$ is "Average", and that of port $P_{3}$ is "Relative Weak". The difference in evaluation results for different ports is obvious.

In order to compare our method with other methods, we neglect the indeterminacy and falsity situations. When only the truth situation is considered, the neutrosophic sets degenerate into the traditional fuzzy sets. Therefore, under the fuzzy set framework, the indicator degrees of Port $P_{k}(k=1$, $2,3)$ can be expressed with the following SVNS information:

$P_{1}=\left\{\left\langle I_{1}, 1.0,0.0,0.0\right\rangle,\left\langle I_{2}, 0.8,0.0,0.0\right\rangle,\left\langle I_{3}, 0.8,0.0,0.0\right\rangle,\left\langle I_{4}, 0.6,0.0,0.0\right\rangle,\left\langle I_{5}, 0.8,0.0,0.0\right\rangle,<I_{6}, 1.0,0.0,0.0\right\rangle$, $\left.<I_{7}, 0.6,0.0,0.0>,<I_{8}, 0.8,0.0,0.0>,<I_{9}, 1.0,0.0,0.0>,<I_{10}, 0.6,0.0,0.0>\right\}$,

$P_{2}=\left\{\left\langle I_{1}, 0.8,0.00 .0\right\rangle,\left\langle I_{2}, 0.6,0.0,0.0\right\rangle,\left\langle I_{3}, 0.4,0.0,0.0\right\rangle,\left\langle I_{4}, 0.8,0.0,0.0\right\rangle,\left\langle I_{5}, 0.6,0.0,0.0\right\rangle,\left\langle I_{6}, 0.6,0.0,0.0\right\rangle\right.$, $\left.<I_{7}, 0.8,0.0,0.0>,<I_{8}, 0.6,0.0,0.0>,<I_{9}, 0.6,0.0,0.0>,<I_{10}, 0.4,0.0,0.0>\right\}$,

$P_{3}=\left\{\left\langle I_{1}, 0.6,0.0,0.0\right\rangle,\left\langle I_{2}, 0.6,0.0,0.4\right\rangle,\left\langle I_{3}, 0.2,0.2,0.6\right\rangle,\left\langle I_{4}, 0.8,0.0,0.2\right\rangle,\left\langle I_{5}, 0.4,0.0,0.0\right\rangle,\left\langle I_{6}, 0.6,0.0,0.0\right\rangle\right.$, $\left.<I_{7}, 0.4,0.0,0.0>,<I_{8}, 0.8,0.0,0.0>,<I_{9}, 0.4,0.0,0.0>,<I_{10}, 0.6,0.0,0.0>\right\}$. 
Similarly, we can get the results of the similarity measure between the port $P_{k}(k=1,2,3)$ and the indicator degree $D_{i}(i=1,2,3,4,5)$ under the traditional fuzzy set framework, as shown in Table 6.

Table 6. Similarity measure values of between $P_{k}$ and $D_{i}$ with Fuzzy Set.

\begin{tabular}{cccccc}
\hline & $S_{\mathbf{1}}$ & $\boldsymbol{S}_{\mathbf{2}}$ & $\boldsymbol{S}_{\mathbf{3}}$ & $\boldsymbol{S}_{\mathbf{4}}$ & $\boldsymbol{S}_{\mathbf{5}}$ \\
\hline$W_{1}\left(P_{1}, D_{i}\right)$ & 0.8999 & 0.8407 & 0.7150 & 0.5531 & 0.4114 \\
$W_{1}\left(P_{2}, D_{i}\right)$ & 0.8038 & 0.8038 & 0.7668 & 0.6308 & 0.4794 \\
$W_{1}\left(P_{3}, D_{i}\right)$ & 0.7775 & 0.7775 & 0.7406 & 0.6391 & 0.5018 \\
\hline
\end{tabular}

From the data in Table 6, we can see that there is a big difference between the evaluation results using fuzzy sets and our method (see Table 5). From the evaluation results of fuzzy sets, the result of port $P_{1}$ is "Strong", that of port $P_{2}$ is "Strong" or "Relative Strong", and that of port $P_{3}$ is also "Strong" or "Relative Strong" (see Table 6). In this way, it is difficult to distinguish the differences among the evaluation results of the three smart ports. Therefore, our evaluation method is much more effective and reasonable than the traditional fuzzy set method. From the case study in this paper, simplified neutrosophic exponential similarity measures can be well used in the evaluation of smart port development and get more reasonable evaluation results. However, from the point of view of the specific research process, this method has not added the influence of decision experts' weight. In the future research, we can consider the influence of decision experts' weight on the evaluation results comprehensively, and further overcome the subjective limitations of expert evaluation, so as to make the evaluation results of smart ports more reasonable and flexible.

\section{Conclusions and Future Directions}

The intelligent operation is an imperative development direction of advanced ports in the future. Securing all-round and sustainable development is the key to enhancing the competitiveness of ports. To this end, it is of more practical significance to study and analyze smart port evaluation. Based on exponential functions, this paper proposes to apply single-valued neutrosophic exponential similarity measure to evaluate smart port in a simplified neutral environment. This evaluation approach is advantageous over other existing port evaluation methods in that it has a more complete evaluation system to render a clearly quantitative evaluation result. Besides, it addresses the decision-making in the context of incomplete, uncertain and inconsistent information for smart port evaluation, making its evaluation results more scientific and rigorous. The contribution of this study is threefold. First, this study makes an initiative for the assessment of world smart port development. Second, this research provides an effective method for the evaluation system of amert ports. Third, the achievements of this study can provide decision-making basis and practical tool for international organizations, relevant governments or policy makers to formulate reasonable and effective governance strategy of global port industry and smart port development.

Using single-valued neutrosophic exponential similarity measure to analyze and evaluate smart port is an innovative attempt. This paper still has limitations. In the future, further research can be carried out focusing on the following three aspects. First, more smart port types and orientations can be taken into consideration in future to further tap to the evaluation of the smart ports using next-generation information technologies, while including different types of data in the evaluation scope to build more accurate evaluation indicators. Second, the evaluation indicators can be further subdivided. In the future, we can further look at the four aspects of smart port, namely the daily production and operation, the logistics supply chain system, the financial and trade services, and the energy conservation and emission reduction, for in-depth research and establishment of a more practical evaluation system that better complies with the actual situations. Third, the probabilistic approach can be introduced into the single-valued neutrosophic exponential similarity measure of this paper to give the evaluation model a certain predictive ability for the future development direction of smart 
ports, helping the port to locate find more room for improvement, so as to elevate the comprehensive competitiveness and put forward more accurate and effective suggestions for port building.

Author Contributions: J.C. and K.X. conceived the research idea, and co-wrote the paper. J.Y. proposed exponential similarity measures (ESMs) between simplified neutrosophic sets (SNSs), including single valued neutrosophic ESMs and interval neutrosophic ESMs. T.H. and Y.T. performed data analysis, established the mathematical models and revised the paper. C.H. and Y.Z. collected the data and revised the paper.

Funding: This paper was supported by the National Natural Science Foundation of China (Grant No. 51879156 and 51409157), Shanghai Pujiang Program (17PJC053), and the Program of Humanities and Social Science of the Ministry of Education of China (14YJC630008).

Conflicts of Interest: The authors declare no conflict of interest.

\section{References}

1. Wu, J.; Yan, H.; Liu, J. DEA models for identifying sensitive performance measures in container port evaluation. Marit. Econ. Logist. 2010, 12, 215-236. [CrossRef]

2. Tongzon, J. Efficiency measurement of selected Australian and other international ports using data envelopment analysis. Transp. Res. Part A Policy A Pract. 2001, 35, 107-122. [CrossRef]

3. Tongzon, J.L. Systematizing international benchmarking for ports. Marit. Manag. 1995, 22, $171-177$. [CrossRef]

4. Kevin, C.; Dong-Wook, S.; Ping, J.; Teng-Fei, W. An application of DEA windows analysis to container port production efficiency. Rev. Netw. Econ. 2004, 3, 1-23.

5. Cullinane, K.; Ji, P.; Wang, T.F. The Relationship between privatization and DEA estimates of efficiency in the container port industry. J. Econ. Bus. 2005, 57, 433-462. [CrossRef]

6. Rajasekar, T.; Deo, M. The size effect of Indian major ports on its efficiency using Dea-Additive models. Int. J. Adv. Manag. Econ. 2018, 1, 12-18.

7. Wang, Y.J.; Han, T.C. Efficiency measurement for international container ports of Taiwan and surrounding areas by fuzzy data envelopment analysis. J. Mar. Sci. Technol.-Taiwan 2018, 26, 185-193.

8. Cullinane, K.; Wang, T.-F. Chapter 23 Data Envelopment Analysis (DEA) and Improving Container Port Efficiency. Res. Transp. Econ. 2006, 17, 517-566. [CrossRef]

9. Gamassa, P.K.P.; Chen, Y. Comparison of port efficiency between Eastern and Western African ports using DEA Window Analysis. In Proceedings of the 2017 14th International Conference on Service Systems and Service Management (ICSSSM), Dalian, China, 16-18 June 2017.

10. Chin, A.; Tongzon, J. Maintaining singapore as a major shipping and air transport hub. In Competitiveness of The Singapore Economy: A Strategic Perspective; Yam, T.K., Heng, T.M., Eds.; World Scientific: Singapore, 1998; pp. 83-114.

11. Barros, C.P.; Athanassiou, M. Efficiency in european seaports with DEA: Evidence from Greece and Portugal. Marit. Econ. Logist. 2004, 6, 122-140. [CrossRef]

12. Tongzon, J.L.; Ganesalingam, S. An evaluation of ASEAN port performance and efficiency. Asian Econ. J. 1994, 8, 317-330. [CrossRef]

13. Chen, J.; Wan, Z.; Zhang, F.; Park, N.K.; He, X.; Yin, W. Operational efficiency evaluation of iron ore logistics at the ports of Bohai Bay in China: Based on the PCA-DEA Model. Math. Probl. Eng. 2016, 2016. [CrossRef]

14. Coto-Millan, P.; Baños-Pino, J.; Rodríguez-Alvarez, A. Economic efficiency in Spanish ports: Some empirical evidence. Marit. Manag. 2000, 27, 169-174. [CrossRef]

15. Cullinane, K.; Song, D.W.; Gray, R. A stochastic frontier model of the efficiency of major container terminals in Asia: Assessing the influence of administrative and ownership structures. Transp. Res. Part A Policy Pract. 2002, 36, 743-762. [CrossRef]

16. Notteboom, T.E.; Winkelmans, W. Structural changes in logistics: How will port authorities face the challenge? Marit. Manag. 2001, 28, 71-89. [CrossRef]

17. Yuhling, S.U.; Liang, G.S.; Chin-Feng, L.I.U.; Tsung-Yu, C.H.O.U. A study on integrated port performance comparison based on the concept of balanced scorecard. J. Eastern Asia Soc. Transp. Stud. 2003, 5, 609-624.

18. Lirn, T.C.; Thanopoulou, H.A.; Beresford, A.K.C. Transhipment port selection and decision-making behaviour: Analysing the Taiwanese case. Int. J. Logist. Res. Appl. 2003, 6, 229-244. [CrossRef] 
19. Chiu, R.-H.; Lin, L.-H.; Ting, S.-C. Evaluation of Green Port Factors and Performance: A Fuzzy AHP Analysis. Math. Probl. Eng. 2014, 2014,1-12. [CrossRef]

20. Onut, S.; Tuzkaya, U.R.; Torun, E. Selecting container port via a fuzzy ANP-based approach: A case study in the Marmara Region, Turkey. Transp. Policy 2011, 18, 182-193. [CrossRef]

21. Brooks, M.R.; Schellinck, T.; Pallis, A.A. A systematic approach for evaluating port effectiveness. Marit. Manag. 2011, 38, 315-334. [CrossRef]

22. Smarandache, F. A unifying field in logics: Neutrosophic logic. Multiple-Valued Logic 1999, 8, 489-503.

23. Fu, J.; Ye, J. Simplified Neutrosophic Exponential Similarity Measures for the Initial Evaluation/Diagnosis of Benign Prostatic Hyperplasia Symptoms. Symmetry 2017, 9, 154. [CrossRef]

24. Peng, J.-J.; Wang, J.-Q.; Zhang, H.-Y.; Chen, X.-H. An outranking approach for multi-criteria decision-making problems with simplified neutrosophic sets. Appl. Soft Comput. 2014, 25, 336-346. [CrossRef]

25. Şahin, R.; Liu, P. Some approaches to multi criteria decision making based on exponential operations of simplified neutrosophic numbers. J. Intell. Syst. 2017, 32, 2083-2099. [CrossRef]

26. Şahin, R.; Küçük, A. Subsethood measure for single valued neutrosophic sets. J. Intell. Syst. 2015, 29, 525-530. [CrossRef]

27. Biswas, P.; Pramanik, S.; Giri, B.C. TOPSIS method for multi-attribute group decision-making under single-valued neutrosophic environment. Neural Comput. Appl. 2016, 27, 727-737. [CrossRef]

28. Şahin, R.; Liu, P. Maximizing deviation method for neutrosophic multiple attribute decision making with incomplete weight information. Neural Comput. Appl. 2016, 27, 2017-2029. [CrossRef]

29. Akram, M.; Shahzadi, S. Neutrosophic soft graphs with application. J. Intell. Fuzzy Syst. 2017, 32, 841-858. [CrossRef]

30. Smarandache, F.; Ali, M. Neutrosophic triplet group. Neural Comput. Appl. 2018, 29, 595-601. [CrossRef]

31. Rizk-Allah, R.M.; Hassanien, A.E.; Elhoseny, M. A multi-objective transportation model under neutrosophic environment. Comput. Electr. Eng. 2018, 69, 705-719. [CrossRef]

32. Liu, P.; Teng, F. Multiple attribute decision making method based on normal neutrosophic generalized weighted power averaging operator. Int. J. Mach. Learn. Cybern. 2018, 9, 281-293. [CrossRef]

33. Abdel-Basset, M.; Mohamed, M. The role of single valued neutrosophic sets and rough sets in smart city: Imperfect and incomplete information systems. Measurement 2018, 124, 47-55. [CrossRef]

34. Thong, N.T.; Dat, L.Q.; Son, L.H.; Hoa, N.D.; Ali, M.; Smarandache, F. Dynamic interval valued neutrosophic set: Modeling decision making in dynamic environments. Comput. Ind. 2019, 108, 45-52. [CrossRef]

35. López, L.F.D.M.; Blas, N.G.; Arteta, A. The optimal combination: Grammatical swarm, particle swarm optimization and neural networks. J. Comput. Sci. 2012, 3, 46-55. [CrossRef]

36. Albert, A.A.; Blas, N.G.; de Mingo López, L.F. Natural combination to trade in the stock market. Soft Comput. 2016, 20, 2433-2450. [CrossRef]

37. López, L.F.M.; Blas, N.G.; Albert, A.A. Multidimensional knapsack problem optimization using a binary particle swarm model with genetic operations. Soft Comput. 2018, 22, 2567-2582. [CrossRef]

38. Angeloudis, P.; Bell, M.G. An uncertainty-aware AGV assignment algorithm for automated container terminals. Transp. Res. E: Logist. Transp. Rev. 2010, 46, 354-366. [CrossRef]

39. Luo, S.; Ren, B. The Monitoring and Managing Application of Cloud Computing Based on Internet of Things; Elsevier North-Holland, Inc.: New York, NY, USA, 2016.

40. Gu, S.; Hua, J.; Lv, T. Evaluation of customer satisfaction of "Door-to-Door" whole-process logistic service with interval-valued intuitionistic fuzzy information. J. Intell. Fuzzy Syst. 2016, 30, 2487-2495. [CrossRef]

41. Zhang, Y.; Zou, D.; Zheng, J.; Fang, X.; Luo, H. Formation mechanism of quick emergency response capability for urban rail transit: Inter-organizational collaboration perspective. Adv. Mech. Eng. 2016, 8. [CrossRef]

42. Cho, H.; Choi, H.; Lee, W.; Jung, Y.; Baek, Y. LITeTag: Design and implementation of an RFID system for IT-based port logistics. J. Commun. 2006, 1, 48-57. [CrossRef]

43. Wang, L. Study on Port Logistics Marketing under the Environment of Supply Chain. Int. J. Bus. Manag. 2011, 6, 267. [CrossRef]

44. Rudjanakanoknad, J.; Suksirivoraboot, W.; Sukdanont, S. Evaluation of International Ports in Thailand through Trade Facilitation Indices from Freight Forwarders. Procedia—Soc. Behav. Sci. 2014, 111, 1073-1082. [CrossRef]

45. Lai, G.; Debo, L.G.; Sycara, K. Sharing inventory risk in supply chain: The implication of financial constraint. Omega 2009, 37, 811-825. [CrossRef] 
46. Peris-Mora, E.; Diez Orejas, J.M.; Subirats, A.; Ibáñez, S.; Alvarez, P. Development of a system of indicators for sustainable port management. Mar. Pollut. Bull. 2005, 50, 1649-1660. [CrossRef] [PubMed]

47. Zhao, M.; Zhang, Y.; Ma, W.; Fu, Q.; Yang, X.; Li, C.; Zhou, B.; Yu, Q.; Chen, L. Characteristics and ship traffic source identification of air pollutants in China's largest port. Atmos. Environ. 2013, 64, 277-286. [CrossRef]

48. Chen, J.; Wan, Z.; Zhang, F.; Park, N.-K.; Zheng, A.; Zhao, J. Evaluation and comparison of the development performances of typical free trade port zones in China. Transp. Res. Part A Policy Pract. 2018, 118, 506-526. [CrossRef]

49. Chen, J.; Huang, T.; Xie, X.; Lee, P.T.-W.; Hua, C. Constructing Governance Framework of a Green and Smart Port. J. Mar. Sci. Eng. 2019, 7, 83. [CrossRef]

50. Wang, H.; Smarandache, F.; Zhang, Y.-Q.; Sunderraman, R. Interval Neutrosophic Sets and Logic: Theory and Applications in Computing; Hexis: Frontignan, France, 2005.

(C) 2019 by the authors. Licensee MDPI, Basel, Switzerland. This article is an open access article distributed under the terms and conditions of the Creative Commons Attribution (CC BY) license (http://creativecommons.org/licenses/by/4.0/). 